\title{
ATMOSPHERIC DISPERSION PATTERNS OF RADIONUCLIDES ORIGINATING FROM NUCLEAR POWER PLANT ACCIDENTS UNDER VARIOUS RELEASE TYPES
}

\author{
EFEM BILGIC ${ }^{1} \&$ ORHAN GUNDUZ ${ }^{2 *}$ \\ ${ }^{1}$ Dokuz Eylul University, The Graduate School of Natural and Applied Sciences, Izmir, Turkey. \\ ${ }^{2}$ Dokuz Eylul University, Department of Environmental Engineering, Izmir, Turkey.
}

\begin{abstract}
Nuclear power has begun to lose its popularity after the major catastrophes of Chernobyl and Fukushima that caused a global environmental and public health problem. Radioactivity released from these accidents spread all around the world and negatively influenced large areas as a result of different meteorological conditions prevailing at the time of the accidents. Another particularly important parameter used in assessing the atmospheric dispersion of radioactivity is the characteristics of the source term that defines the release pattern of radionuclides from the accident site. Core inventory and shape and extent of the release define the source term to be used in simulating the dispersion pattern of radioactivity. Thus, mathematical representation of the source term is a crucial part of the dispersion modeling of radionuclides. Ideal types of releases (such as pulse, step, linear, sinusoidal) can occur in an accident or a combination of these types can constitute the real pattern of the release from the accident's source. The mathematical character of the release is influential in the overall dispersion and deposition of radioactivity. Based on this premise, this study is conducted to assess the possible differences in the spatial distribution of dispersed and deposited radionuclides that can originate from a potential accident in Akkuyu nuclear power plant (NPP) in the southern Mediterranean coast of Turkey. Simulations are performed with FLEXPART model to predict the atmospheric dispersion and ground level depositions of radionuclides to be released from a hypothetical accident in Akkuyu under various release patterns and different meteorological conditions representing extreme conditions. Model simulations considered a 10-day release duration with distinct release patterns under extreme meteorological conditions for the site. A comparative assessment is then conducted to evaluate the extent and magnitude of Cs-137 dispersion and deposition, which is the most commonly used radionuclide in NPP accident simulations. Keywords: Akkuyu, Atmospheric dispersion modeling, Nuclear Power Plant Accidents, Source Term.
\end{abstract}

\section{INTRODUCTION}

Although considered to be a debatable technology, nuclear energy still has a significant share in electricity generation in the world. Today, there are 450 nuclear power reactors in operation [1] and has an approximate share of $10 \%$ in total electricity production [2]. However, ecological and public health concerns are now considered to be the single most important aspect of nuclear power generation. Despite its catastrophic consequences under accident conditions, some still consider nuclear power as an environmentally friendly technology as it does not emit greenhouse gases like fossil-fired power plants, and renewable energy technologies have not reached sufficient levels to supply high electricity demands. Thus, analysts presume nuclear energy will retain its significant share and importance in electricity generation in the near future. U.S. Energy Information Administration (EIA) estimated the share of nuclear energy in total generation to be around 10\% in the year 2040 [3].

Despite the importance of nuclear power generation in global electricity production and its advantages in the climate change phenomenon with regards to its comparably low greenhouse gas emissions, the environmental disadvantages of nuclear technology are yet to be resolved. Radioactive releases into the environment are now considered to be the most 
significant negative impact of this technology. Catastrophic accidents like Chernobyl (Soviet Union), Fukushima (Japan) and Windscale (United Kingdom) has created major global scale problems, the aftermaths of which, are still observed in all environmental matrices. Scientists use mathematical models to estimate the atmospheric movement and dispersion of radioactive releases that occurred from these accidents and further utilize these models to predict the potential scattering patterns that might occur from future accidents.

Atmospheric dispersion models used in simulating the distribution of radioactivity use Eulerian or Lagrangian approaches [4]. Both approaches require basic information regarding the source terms and regional meteorology. The source term data are typically considered to be one of the most important piece of information in simulating the dispersion pattern of radionuclides. It contains types of contaminant species, release amount, changing release patterns over time and vertical location of the species in the atmosphere. These parameters considerably influence simulation results and the prediction of these variables is complicated. In particular, it is quite difficult to accurately determine the actual release pattern of radionuclides from an accident. Based on this premise, this study intends to understand the potential consequences of various time-dependent release patterns on the overall dispersion and deposition of radionuclides. Five different mathematical release functions (step, pulse, triangular, exponential, Log Pearson III) were used to simulate the extent of dispersion and the deposition of radioactivity in a time-dependent manner. The simulations were conducted with a Lagrangian dispersion model, FLEXPART, and the most commonly cited radionuclide in literature (Cs-137) for nuclear power plant (NPP) accidents was used in mode runs. The tests were conducted for a hypothetical accident to occur in Akkuyu NPP that is being constructed at the Mediterranean coastline of Turkey.

\section{METHODOLOGY}

\subsection{Lagrangian dispersion modeling}

Numerical simulation of the transport of air pollutants can be performed with Eulerian or Lagrangian approaches. The main difference between the Eulerian and Lagrangian approaches is that the reference coordinate system is fixed in the Eulerian approach whereas the Lagrangian reference system follows the average atmospheric motion [4].

The well-known Lagrangian particle model, FLEXPART, that is commonly used in atmospheric dispersion modeling studies, was used in this study. FLEXPART can be used in backward and forward modes, considers zero acceleration scheme to estimate the atmospheric motion (eqn.1)[5]

$$
\mathrm{X}(\mathrm{t}+\Delta \mathrm{t})=\mathrm{X}(\mathrm{t})+\mathrm{v}(\mathrm{X}, \mathrm{t}) * \Delta \mathrm{t}
$$

where $\mathrm{X}$ is the position vector, $\Delta \mathrm{t}$ is the time increment and $v$ is the wind vector that is composed of the grid scale wind, the turbulent wind fluctuations and the mesoscale wind fluctuations. Grid scale wind and turbulent wind fluctuations can be calculated with Langevin equations and mesoscale wind fluctuations was estimated with a method similar to Markov's (reference) equations in FLEXPART [5]. Radioactive decay and dry/wet deposition were used as removal mechanisms in the model. All equations about removal processes and model processes are presented in Stohl et al.'s technical documents [5]. The radionuclide concentration in a grid cell is then calculated by sampling the tracer mass fractions of all particles within the grid cell and dividing by the grid cell volume. The computed concentrations and deposition values are then spatially analyzed with a GIS software. 


\subsection{Release types}

Radionuclides originate from nuclear accidents spread at regional and global scales with atmospheric motion and negatively influence large areas as a result of wet and dry depositions under different meteorological conditions. Beside meteorological parameters, the characteristics of the source term are extremely important in determining the dispersion pattern. The source term contains information regarding the core inventory and the shape and extent of the release. Accurate mathematical representation of the release is crucial to assess the atmospheric dispersion of radionuclides. Five different release types were investigated in this study: (i) step input, (ii) pulse input, (iii) exponential input, (iv) triangular input and (v) log Pearson type III input. The step input represents a release that is held constant for the entire simulation period. The step release was also considered to be the base scenario to compare with the results of other release types. The second release type is called the pulse input, which defines a situation where all radionuclides are released to the atmosphere instantaneously and is formulated by a Dirac Delta function. In the Exponential input, the radionuclide is released in an exponential manner and gradually decreased to reach zero at the end of the release period. The fourth type, triangular release, is named after the shape of release pattern that demonstrates the shape of an isosceles triangle. The release starts from zero, reaches a maximum point at the middle of the release by a linear increase, and later linearly decrease to zero at the end of the release. The last type of release follows the log Pearson Type III function equation. The shapes of released used in simulations are presented in Fig. 1. In all release types, the unit of release is Becquerel per hour $(\mathrm{Bq} / \mathrm{hour})$, which is a measure of radioactivity in the SI system.

\section{APPLICATION}

\subsection{Study area}

Turkey plans to construct two NPPs, one of which is the Akkuyu NPP located at the southern coasts of Turkey. This plant was selected to be the study area for this research. The Akkuyu NPP will have four reactors and a total installed capacity of 4800 MWe. The plant will generate about 35 billion kWh electricity per year [6]. The plant is situated in Mersin Province, which is located at the Mediterranean coastline of Turkey to the north of the island of Cyprus. Akkuyu NPP is situated on the coast in Gulnar district in Mersin Province. Although the plant is located at sea level, elevation shows a rapid increase towards the inland direction where Taurus Mountains serve as a natural barrier that causes the fundamental climatological differences between Mediterranean and central Anatolian regions.

According to Köppen Geiger climate classification, Mersin has 'csa' type climate with hot and dry summers and warm and rainy winters. Dominant winds at the power plant region are from northwest to southeast in winters and from southwest to northeast in summers. The characteristic wind direction and speed are the two major parameters influencing the dispersion pattern in the region.

\subsection{Meteorological data}

FLEXPART model utilizes ECMWF and GFS (NCEP) data as the meteorological input. 6-hourly NCEP data with $0.5 \times 0.5$ degree resolution were used in this study. Because the main purpose of this study is to compare the influence of different release types on the dispersion pattern of radionuclides, a simulation period with minimum removal mechanisms 
(i.e. a period of no wet deposition) was selected by analyzing long-term meteorological conditions of the region. Based on this motive, the simulation period used in this study was August 2010, which was the hottest and driest period in the meteorological history of the area.

\subsection{Source term}

Cs-137, one of the most commonly used radionuclide in modeling activities of nuclear accidents, is also used in this study as the representative radioelement for modeling radioactivity. Radioactive decay is neglected in simulations as Cs- 137 has about 30 years of half-life time whereas the simulation period was only 10 days. Default values defined in FLEXPART were used for parameters related to wet and dry depositions estimations. The total amount of radioactivity released is mimicked from the values calculated after Chernobyl and Fukushima accidents. Studies report that nearly $86 \mathrm{PBq}$ of Cs-137 released into atmosphere after Chernobyl NPP accident [7]. This value was in the order of 20-26 PBq for Fukushima NPP accident [8]. Accordingly, the Cs-137 release is taken to be $100 \mathrm{PBq}$ for the simulations conducted in this study. While this is slightly higher than that of Chernobyl, it is a fairly reasonable value that can accurately fit to all different release types discussed before. In addition, the release period is taken to be 10 days, which is equal to the total release duration of Chernobyl accident. Consequently, all release functions shown in Fig. 1 are formed so that the total amount of Cs-137 release will cumulatively sum up to $100 \mathrm{PBq}$ in the total release duration of 10-days (Fig. 1).
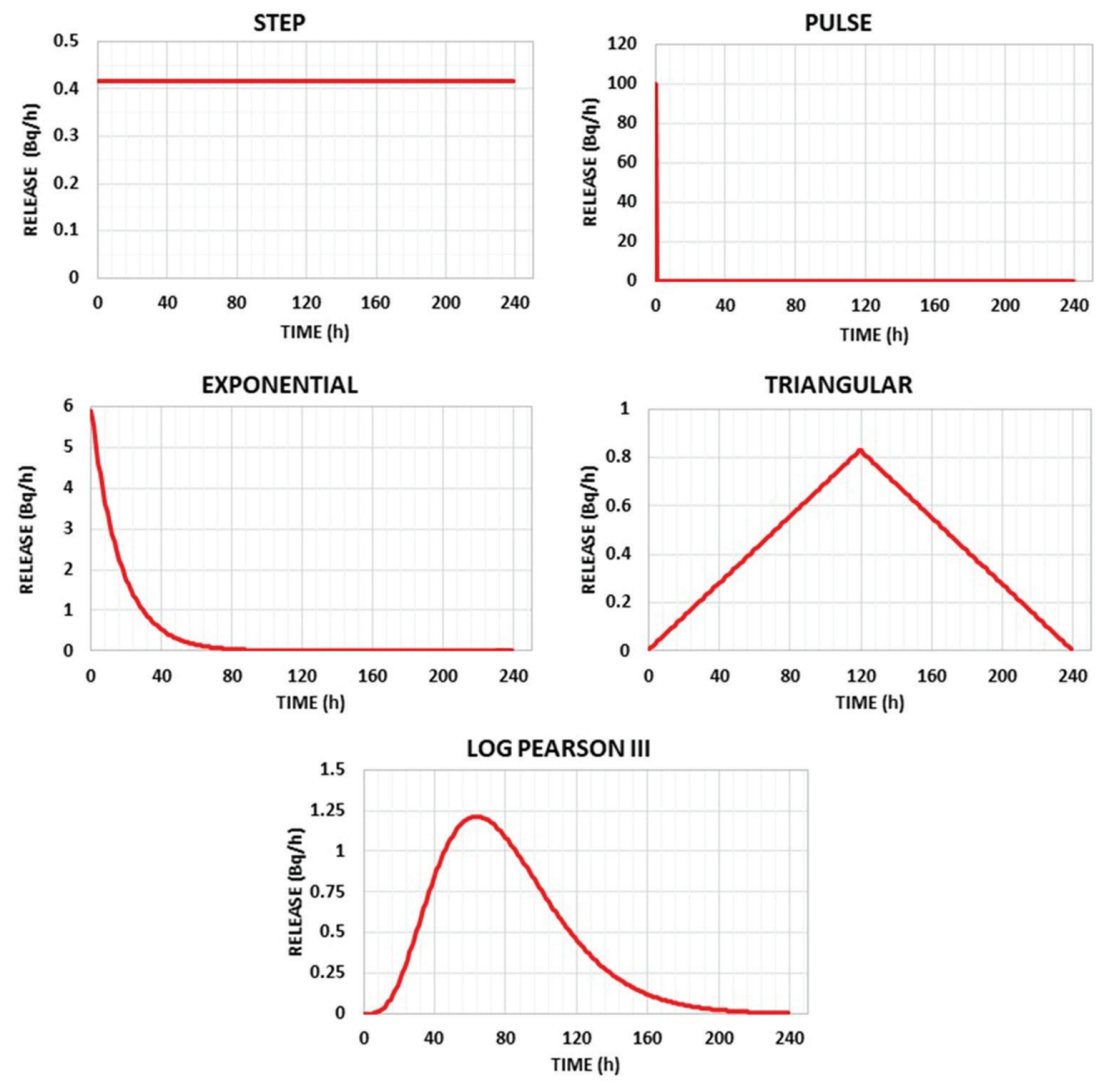

Figure 1: Release functions used in this study. 
Another important parameter in source term is the total vertical level that the release could reach considering the fact that radionuclides released from nuclear accidents ascend to different vertical levels in the atmosphere. Brand et al. [9] estimated that Cs-137 can reach up to $2225 \mathrm{~m}$ height in the first two days, later descend to $1090 \mathrm{~m}$ height on the third day and can pass below $425 \mathrm{~m}$ height afterwards. Evangeliou et al. [10], on the other hand, estimated that Cs-137 oscillates between 0 and $3000 \mathrm{~m}$ during the release. As the main aim of the study was to assess the influence of release types on the dispersion patterns, the influence of vertical level of release was not examined and an average vertical ascend height was considered based on available literature. Accordingly, Cs-137 was assumed to be homogeneous in the $0-1500 \mathrm{~m}$ column during the entire release period for the entire 10 days of the release duration.

\section{RESULTS}

Simulations were conducted by using FLEXPART for 5 different source terms. Step release was accepted as the reference case (Base scenario) for comparison. According to simulations, atmospheric motion during August 2010 period moves radioactivity clouds generally towards south and east directions. Radioactivity moves to south direction at the first hour of release, then turns east at the end of the first day. After the fifth day, radioactive clouds begin to move towards north and influence Anatolian Peninsula. Later, radioactive contamination spread all around Turkey and the environs and starts to move towards south direction again after the seventh day. After the 10th day, air concentrations start to decrease as the release stops (Fig. 2).

The deposition maps follow a pattern similar to the dispersion maps. The deposition values demonstrate elevated levels in areas where dispersion moved the radionuclides as a result of the meteorological conditions. As expected, the maximum values were observed around Akkuyu NPP. At the end of the release period, high deposition values were obtained over southeast of Turkey, inner Anatolia and Syria according to the model results. The central deposition values for Cs-137 corresponded to about $1 \mathrm{kBq} / \mathrm{m}^{2}$, which followed a boundary that passes from north and west of the accident site (Fig. 3).

The Pulse release defines the case when radionuclides are released from the accident site in an instantaneous manner. While such a condition is not typically observed in NPP accidents, it provides a good reference frame for comparison when all the load is disposed to the environment at once. Nevertheless, as deposition is also a strong function of the regional meteorology, instantaneous release conditions not always result in highest depositions as shown in Fig. 4. Accordingly, lower deposition values were observed in Pulse release scenario in Mersin city where Akkuyu NPP was located when compared to its counterpart in Step release scenario. Furthermore, southeast Anatolia and Syria receive lower deposition values in this type release. On the other hand, considerable increase was observed at western and southwestern parts of Turkey, which was thought to have originated from short-term atmospheric motion occurring to the west at first few days of the accident (Fig. 4).

In exponential release, higher deposition values were found in southeast parts of the accident site when compared to step release (Fig. 5). However, values were found to be less than their corresponding values that occurred in pulse release. Thus, it can be claimed that higher releases of the exponential input created more deposition in first days of simulation and this was mostly observed in western Turkey as a result of the predominant western atmospheric movement in the first few days of the runs. Although the magnitude of the deposition is not the same with that of step release, the spread of contamination were found to cover large areas as in the case of step release. On the other hand, heavy deposition in the central Anatolia in Step release was not been observed in this release (Fig. 5). 

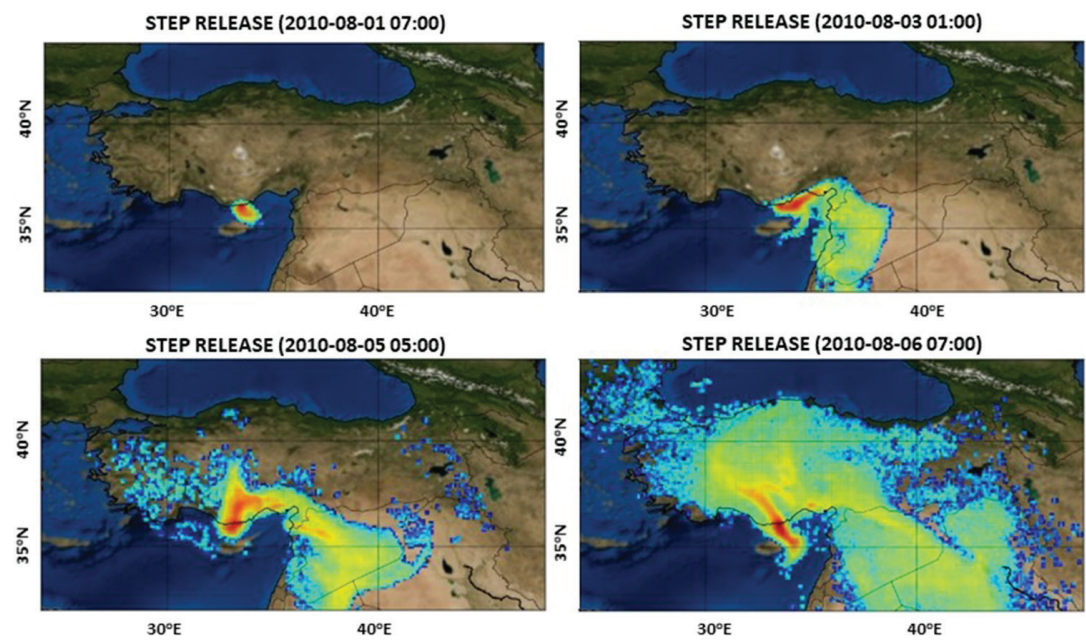

STEP RELEASE (2010-08-07 09:00)
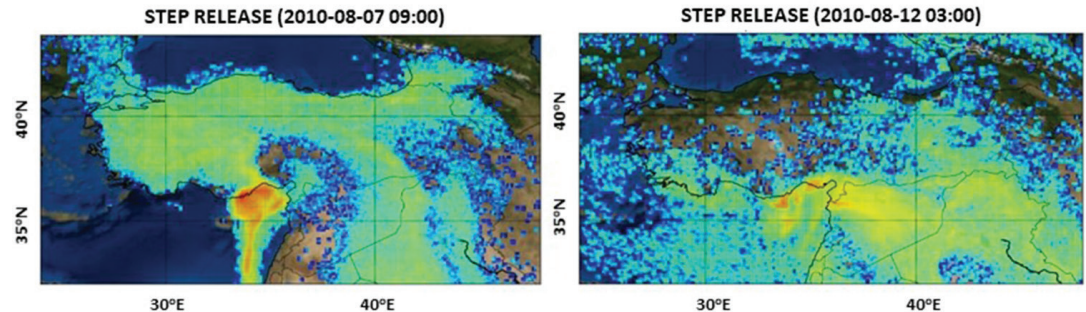

STEP RELEASE (2010-08-14 10:00)

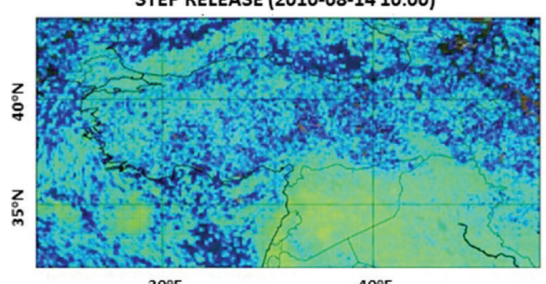

STEP RELEASE (2010-08-16 00:00)
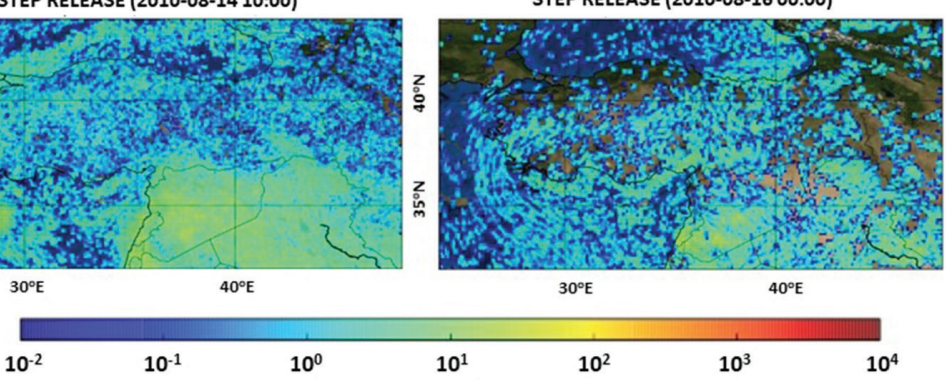

Figure 2: Time-dependent atmospheric dispersion of Cs-137 under step release (Base scenario).

In triangular and log Pearson-type releases, the distributions of depositions are not homogenous when compared to other release types. Ground level depositions of both two releases are scatteredly distributed within the analysis domain. This situation causes considerably lower values to be observed in Eastern Turkey or some regions of the Black Sea. It is also clearly seen that triangular release resulted in a relatively more irregular pattern than logPearson III release. The cause of this irregularity is associated with the linear increase and decrease of source term function. On the other hand, higher deposition values was found in the both release types around Akkuyu NPP accident site, central Anatolia and western Syria which were found to be similar to Step release (Figs. 6, and 7). As the majority of the radioactivity was released at the beginning of the simulations, the influence of meteorological 


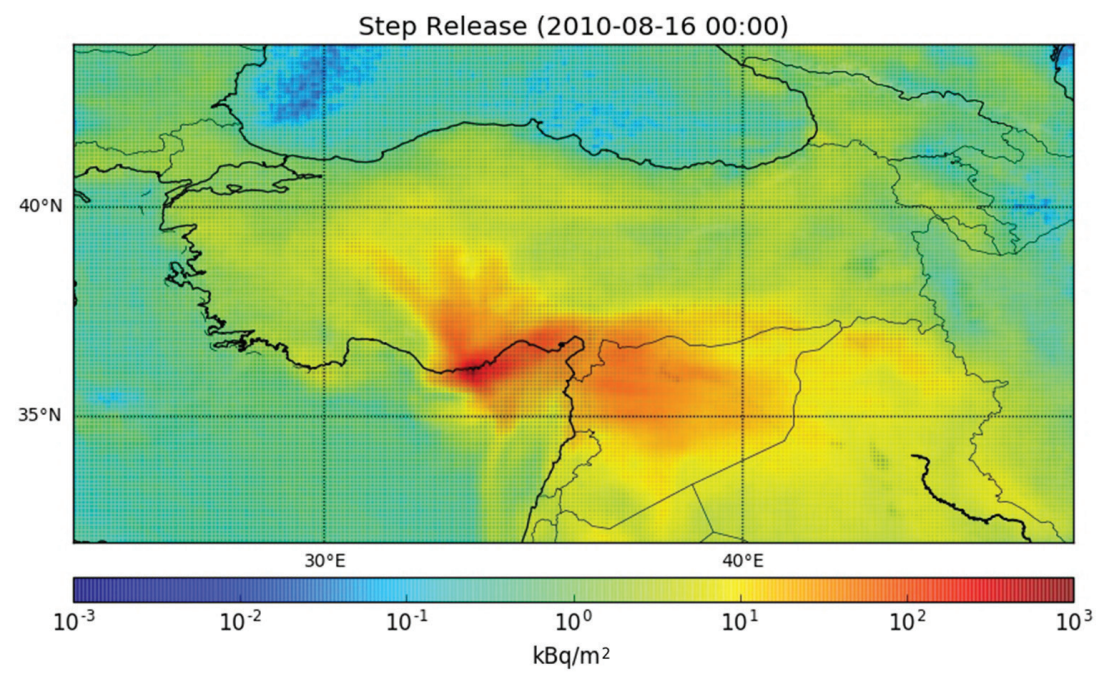

Figure 3: Ground level deposition of Cs-137 under step release $\left(\mathrm{kBq} / \mathrm{m}^{2}\right)$.

factors was far more dominant in the first day of the release for Pulse and Exponential release patterns. Thus, meteorological conditions prevailing at the time of the accident is more influential in the dispersion patterns of release types that are characterized by more simultaneous emissions from the source.

The results were further analyzed with a geographical information system software (ArcGIS v.10.3) and comparisons of each release function were made with respect to the step release that was considered to represent the base conditions. The international country borders of Turkey were considered as the analysis domain and deviations of depositions from the base conditions are comparably evaluated for each release type on a pixel by pixel basis. As a result, triangular release revealed higher deposition values within the country when

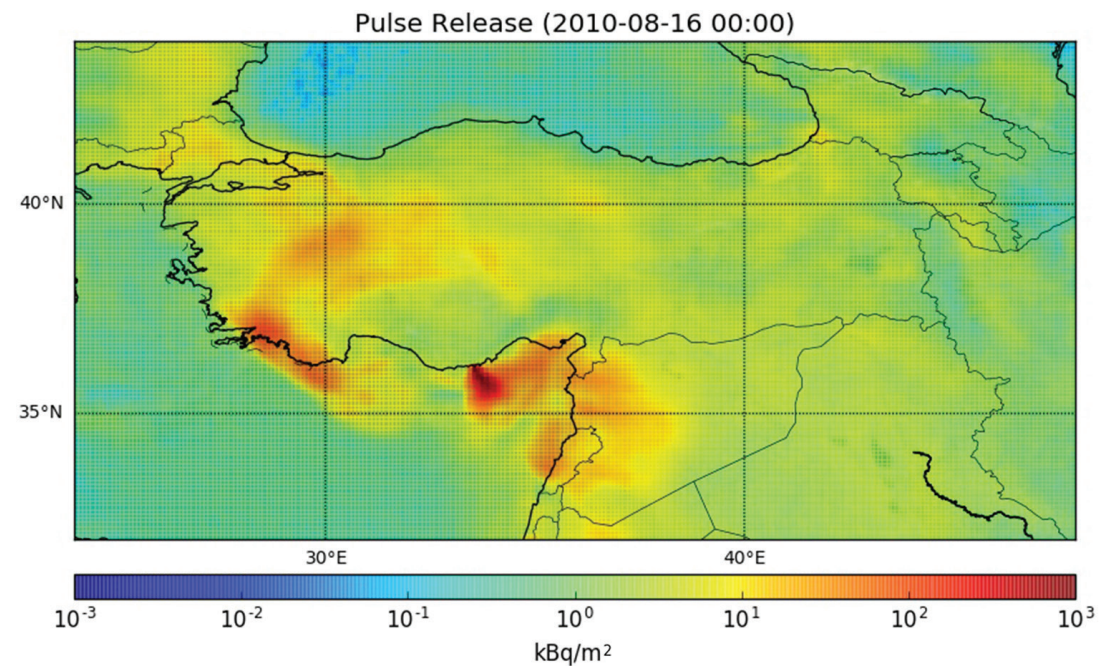

Figure 4: Ground level deposition of Cs-137 under pulse release $\left(\mathrm{kBq} / \mathrm{m}^{2}\right)$. 


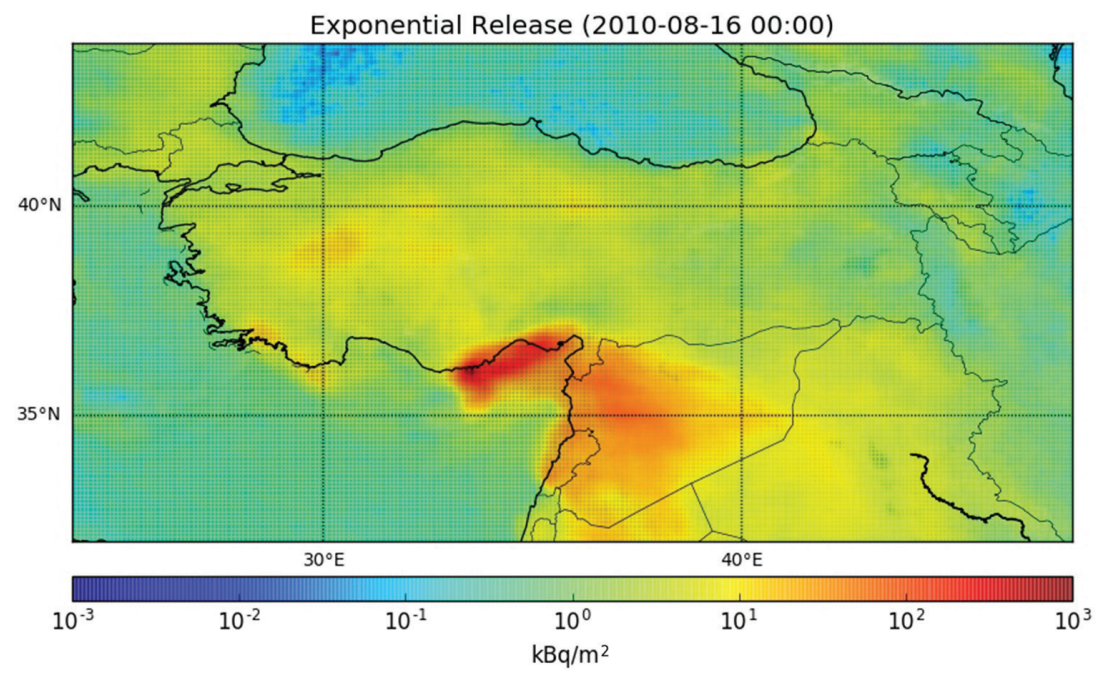

Figure 5: Ground level deposition of Cs-137 under exponential release $\left(\mathrm{kBq} / \mathrm{m}^{2}\right)$.

compared to the depositions occurring from step release. The depositions associated with other release types were found to be less than the step release depositions. In addition, pulse, exponential and log Pearson III-type releases created depositions that are higher in magnitude than step release in some areas such as the southern and eastern Anatolia and eastern Mediterranean. In all other regions of the country, Step release created higher deposition values. On the other hand, when triangular release depositions were compared with step release depositions, radical changes and were observed in neighboring pixels due to bullet-like clusters of the deposition values as a result of smoothly increasing/decreasing source terms of triangular and log Pearson-type III (Table 1).

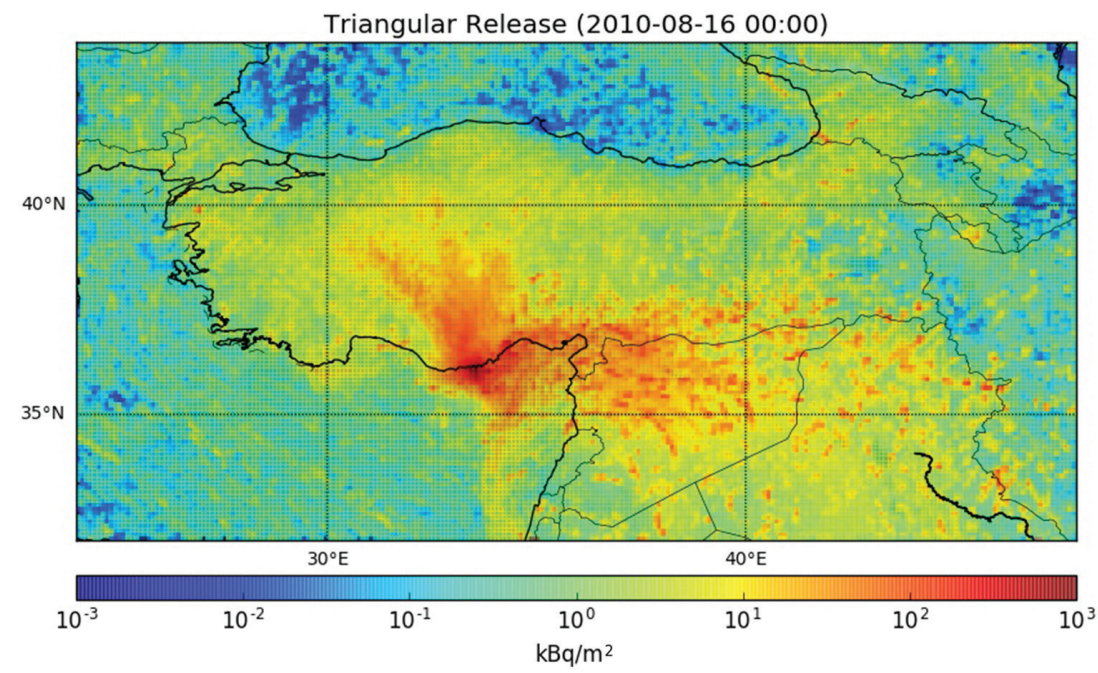

Figure 6: Ground level deposition of Cs-137 under triangular release $\left(\mathrm{kBq} / \mathrm{m}^{2}\right)$. 


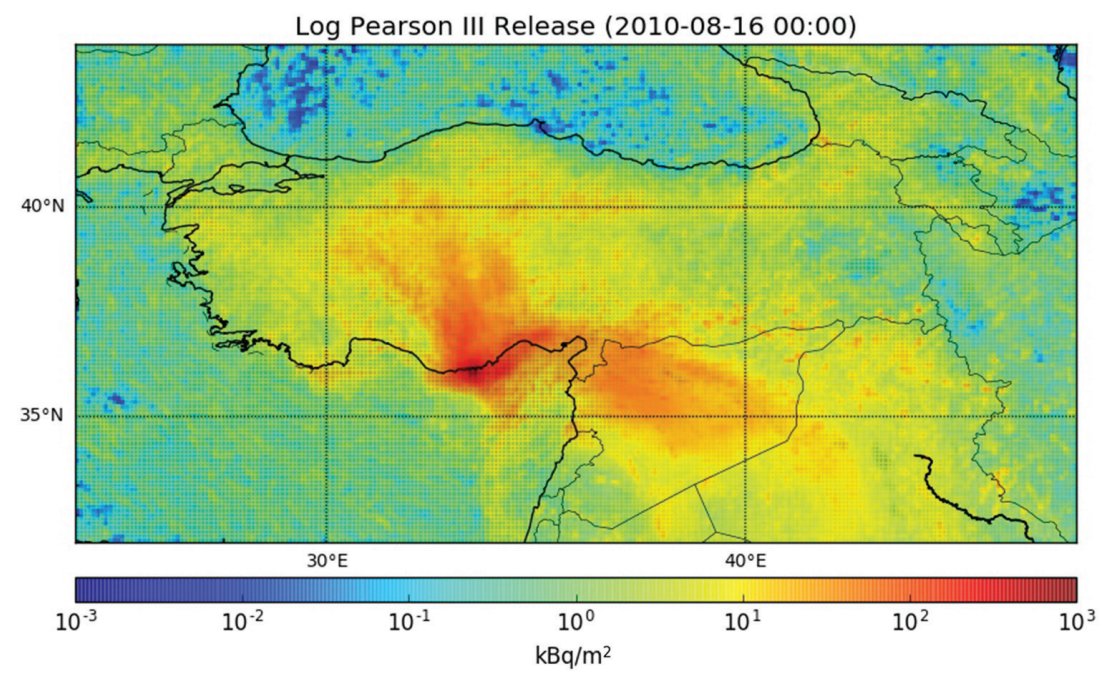

Figure 7: Ground level deposition of Cs-137 under log Pearson III release $\left(\mathrm{kBq} / \mathrm{m}^{2}\right)$.

Table 1: Relative differences of areal distributions for each source terms from step release.

\begin{tabular}{lc}
\hline Release type & Percentage of deposition pixels higher than step release \\
\hline Pulse & $33.67 \%$ \\
Exponential & $46.90 \%$ \\
Triangular & $54.17 \%$ \\
Log Pearson III & $31.93 \%$ \\
\hline
\end{tabular}

The comparisons of total percentage of deposition pixels higher than the step release have shown that the deposition values of $33.67 \%$ of all pixels covering the country were higher in pulse release whereas, in $66.33 \%$ of all pixels, Step release depositions were found to be higher. From the same token, $54.17 \%$ of all pixels had deposition values that are larger in triangular release conditions. Thus, one can conclude that Triangular release had comparably more areas where depositions are larger than that of step release, and log Pearson III had the lowest areal coverage where depositions are higher than that of step release.

\section{CONCLUSIONS AND RECOMMENDATIONS}

This study showed that the source term significantly influences the distribution of radionuclides that originate from a power plant accident. The temporal variations in the release pattern and the associated meteorological conditions during this period strongly influence deposition patterns in the close and far vicinity of the accident site. The simulations showed that triangular release pattern, which shows a linear increase till the peak value and a linear decrease thereafter, had not only the highest maximum deposition value but also the largest contaminated 
area when compared to other release types of step, exponential, log Pearson III and pulse for the simulation conditions presented herein.

The results also clearly indicated that although the same amount of radionuclides is released from the accident site, areas that are influenced from these depositions significantly varied in each release case. In particular, triangular release has been shown to deposit highest radionuclide amounts to the ground around the region between the accident site and Central Anatolia. Pulse release depositions, on the other hand, had lower values in magnitude in the same area. Among the five release types studied in here, instantaneous release (pulse), constant release (step) and exponentially decaying release (exponential) were found to be the types that created more uniform deposition distributions on ground. Triangular and log Pearson III-type release patterns, on the opposite extreme, had temporarily varying release rates that eventually created irregular deposition values. In particular, sharply increasing/decreasing pattern of triangular release revealed the highest irregularity in deposition values.

This study was conducted for only one meteorological period. Although it was selected to represent the extreme conditions at the accident site, one cannot generalize the results to other meteorological conditions and additional simulations need to be performed to assess the influence of these settings. It must also be mentioned that the response of a release function might differ from one meteorological condition to the other. Deposition envelop curves covering the entire spectrum of meteorological conditions need to be generated for each release pattern, which can then be used to reach more concrete conclusions about the severity of a release pattern on the environment. In addition, the vertical ascend height of the release is also a critical factor in the dispersion of radionuclides. This study only considered an average maximum height and a homogeneous distribution within this height. However, available literature from past nuclear accidents report that vertical distribution of release also significantly effects the dispersion of radionuclides. Hence, vertically inhomogeneous conditions need to be simulated as a further research to cover the potential consequences of the vertical distributions of a release.

Finally, this study only considered Cs-137 as the contaminant specie. Although it is the most studied radionuclide used in power plant accident simulations, other species might behave differently under distinct release types. Hence, this study can be extended towards the direction of investigating different radionuclides originating from NPP accidents.

\section{REFERENCES}

[1] International Atomic Energy Agency (IAEA), Nuclear Power Reactors in the World, Reference Data Series No. 2nd edn., IAEA, 2018.

[2] International Energy Agency (IEA), World: Electricity and Heat for 2015. https://www. iea.org/statistics/statisticssearch/report/?country=WORLD\&product=electricityandhea t\&year=2015 (accessed 3 June 2018).

[3] U.S. Energy Information Agency (EIA), International Energy Outlook 2017, EIA, 2017.

[4] Zannetti, P., Air Pollution Modeling: Theories, Computational Methods and Available Software, Southampton: Computational Mechanics Publications, 1990.

[5] Stohl, A., Forster, C., Frank, A., Seibert, P. \& Wotawa, G., Technical note: The Lagrangian particle dispersion model FLEXPART version 6.2. Atmospheric Chemistry and Physics, 5(9), pp. 2461-2474, 2005. https://doi.org/10.5194/acp-5-2461-2005

[6] Republic of Turkey Ministry of Energy and Natural Resources (MENR). Nuclear Power Plant Projects of Turkey: Questions and Answers, Publication of the Office of Nuclear Energy Project Application, 2016. (Original in Turkish). 
[7] United Nations Scientific Committee on the Effects of Atomic Radiation (UNSCEAR). UNSCEAR 2000 Report - Volume II: Sources and Effects of Ionizing Radiation, New York, 2000.

[8] United Nations Scientific Committee on the Effects of Atomic Radiation (UNSCEAR). UNSCEAR 2013 Report - Volume I: Sources, Effects and Risks of Ionizing Radiation, New York, 2014.

[9] Brand, J., Christensen, J.H. \& Frohn, L.M., Modelling transport and deposition of cesium and iodine from the Chernobyl accident using the DREAM model. Atmospheric Chemistry and Physics, 2(5), pp. 397-417, 2002. https://doi.org/10.5194/acp-2-397-2002

[10] Evangeliou, N., Hamburger, T., Cozic, A., Balkanski, Y. \& Stohl, A., Inverse modeling of the Chernobyl source term using atmospheric concentration and deposition measurements. Atmospheric Chemistry and Physics, 17(14), pp. 8805-8824, 2017. https://doi.org/10.5194/acp-17-8805-2017 